cohort receiving subcutaneous therapies. This approach unlocks the potential of "personalised medicine" which supports individualised treatment and brings significant savings to the healthcare provider.

Disclosure of Interest: None declared

DOI: 10.1136/annrheumdis-2018-eular.3116

\section{AB0847 IMPACT OF SPONDYLOARTHRITIS ON LIFE QUALITY BEFORE AND AFTER TREATMENT}

X. Grapton ${ }^{1}$, on behalf of CREER, P. Lemesle ${ }^{2}$, on behalf of CREER, L. Arabian ${ }^{3}$, on behalf of CREER, V. Strotz ${ }^{4}$, on behalf of CREER. ${ }^{1}$ Private Rheumatology Practice, Colombes; ${ }^{2}$ Private Rheumatology Practice, Bois-Colombes; ${ }^{3}$ Private Rheumatology Practice, Clamart, ${ }^{4}$ Private Rheumatology Practice, Antony, France

Background: Life quality issues in spondyloarthritis (SPA) are often spontanously mentioned by patients or identified by rheumatologists. Besides classic follow up parameters, we have to consider those issues to improve our patients life quality.

Objectives: Explore and quantify the impact of SPA on life quality via everyday's life and psychological items and the effect of treatment on them.

Methods: SPA cases were collected by a group of 14 private practice rheumatologists $(\mathrm{Rh})$ in the Paris area. Basic informations about the patient and his disease were provided by his rheumatologist. Questionnaire including 12 themes and 41 items was filled in by the patient.

Results: 50 cases collected, $59.5 \%$ men, mean age 45 years, $82 \%$ working Axial SPA $42 \%$, peripheric $4 \%$, mixt $52 \%$. Mean duration before study: 14 years. Moderate disease $57 \%$, severe $26,5 \%$. HLA B27 positive $84 \%$

Drugs: NSAIDS 96\%, classic DMARDS 31\%, biological DMARDS 84\%, corticosteroids $36 \%$, combination therapy $42 \%$.

Associated measures were suggested by the Rh: Physical activity (62\%), rest (56\%), psychological support, physiotherapy, yoga, adapting professionnel activity and environment..

Life quality issues are spontaneously mentioned by $40 \%$ of the patients.

Before treatment, $72 \%$ of the patients report consequences on their hobbies, $68 \%$ on their psychological well-being, $54 \%$ on their getting about, $50 \%$ on their family relations. The less impacted items are food (26\%) and economy (24\%).

Life quality is mostly altered by pain $(71 \%)$, then fatigue $(17 \%)$, handicap $(7 \%)$ and other people's attitude (5\%).

After treatment, social repercussions diminish by $47 \%$, then getting about, housework, family relations, holidays, sexual life, psychological well-being, hobbies and work (between $-21 \%$ and $-44 \%$ ).

Drug intolerance: $36 \%$

The items improving by more than $50 \%$ after treatment are in this order: cultural life, transports, house-keeping, do-it-yourself, sleep, going out, work (53\% less sick leave).

The treatment is less efficient $(<22 \%)$ on economy, dependance, disillusion, depression and sexual life.

Family circle lacks empathy in $66 \%$ of the cases, family relations stay difficult after treatment.

Conclusions: SPA diminishes quality of life in $75 \%$ of our patients, but only $40 \%$ mention it spontaneously. All the parameters impacted by SPA were significantly improved after treatment. The best improvement concerned hobbies, including culture, do-it-yourself and going out. One patient of two found correct sleep and felt psychologically better. Sick leave was reduced by half, but, unfortunately, family relations didn't improve.

The rheumatologist has to track, in a trusting patient-physician relation, the daily situation impacted by the SPA.

Disclosure of Interest: None declared

DOI: 10.1136/annrheumdis-2018-eular.2279

\section{Spondyloarthritis - clinical aspects (other than treatment)}

\section{$\mathrm{AB} 0848$ \\ FOUR YEARS OF DELAY IN THE DIAGNOSIS OF SAPHO SYNDROME: SINGLE TERTIARY CENTRE EXPERIENCE}

A. Erden ${ }^{1}$, M. Ekici ${ }^{2}$, B. Armagan ${ }^{1}$, A. Sari ${ }^{1}$, G.K. Yardımcl ${ }^{1}$, L. Kilic ${ }^{1}$, S. Apras Bilgen ${ }^{1}$, A. Akdogann ${ }^{1}$, O. Karadag ${ }^{1}$, S. Kiraz ${ }^{1}$, I. Ertenli', U. Kalyoncu' . ' Division of Rheumatology, Department of Internal Medicine; ${ }^{2}$ Department of Internal Medicine, Hacettepe University, Ankara, Turkey

Background: SAPHO syndrome is a chronic disease with bone, joint and skin involvement characterised by synovitis, acne, pustulosis, hyperostosis and osteitis. It is a rare disease and its diagnosis may depend on detailed clinical examination as well as radiological evaluation
Objectives: In this study, we aim to present clinical features and diagnostic course of patients with SAPHO syndrome who are followed in our tertiary referra clinic.

Methods: All patients with SAPHO syndrome diagnosed since February 2014 have been registered with a standard form. Patients are prospectively monitored since then. Diagnosis was based on the criteria by Benhamou et al.. ${ }^{1}$ In the questionnaire, demographic data (age, sex, duration of illness), clinical features (skin and joint involvement), laboratory characteristics (acute phase reactants, HLA B27), radiological imaging (bone scintigraphy (increased activity in the sternum, bilateral sternoclavicular joints and clavicles), MRI) disease activity parameters (BASDAI, BASFI) were questioned. There were 24 patients with SAPHO syndrome. The data of 21 patients were presented because the clinical findings of 3 patients were insufficient.

Results: Data of 21 patients with SAPHO syndrome were available and 11 $(52.4 \%)$ patients were female. Mean age at diagnosis was $39.9 \pm 12.9$, mean age of symptom onset was $35.2 \pm 12.9$, mean follow-up duration was $18.1 \pm 25$. months. The mean delay time of diagnosis SAPHO syndrome was calculated as $49.0 \pm 82.5$ months. Thirteen patients $(61.9 \%)$ were followed up with another clinical diagnosis before SAPHO diagnosis. The clinical characteristics of the patients are shown in Figure 1. HLA-B27 was positive in 3 of 13 patients. Mean activity scores of our patients at initial visit were; BASDAI: $4.8 \pm 2.8$, BASFI: $4.6 \pm 2.2$ CRP2.3 $\pm 4.2 \mathrm{mg} / \mathrm{dL}$ and erythrocyte sedimentation rate $23.8 \pm 22.6 \mathrm{~mm} / \mathrm{h}$. Scintigraphy findings were positive in $16(94.1 \%)$ of 17 patients. The diagnosis of 2 patients was supported by MRI. The remaining 2 patients were diagnosed with $X$ ray and clinic findings.

\begin{tabular}{|c|c|}
\hline Involvement pattern & $n(\%)$ \\
\hline Spinal involvement & $14(66.7)$ \\
\hline Peripheral joint involvement & $8(38.1)$ \\
\hline Skin involvement & $16(76.2)$ \\
\hline - PPP & $10(47.6)$ \\
\hline - Serious acne & $5(23.8)$ \\
\hline - Psoriasisvulgaris & $5(23.8)$ \\
\hline - Hidradenitis suppurativa & $1(4.8)$ \\
\hline \multicolumn{2}{|l|}{ Skin involvement time } \\
\hline - Before muscle skeletal symptoms & $7(43.8)$ \\
\hline - Muscle skeletal symptoms at the same time & $1(6.3)$ \\
\hline - After musculoskeletal symptoms & $8(50)$ \\
\hline Osteoarticular symptoms & $19(90.5)$ \\
\hline Cervical pain & $10(47.6)$ \\
\hline - Thoracic pan & $15(71.4)$ \\
\hline - Lumbosacral pain & $15(71.4)$ \\
\hline Anterior chest wall pain & $20(95.2)$ \\
\hline IBP & $12(57.1)$ \\
\hline Morning st iffness (more than 1 hour) & $10(47.6)$ \\
\hline Ste mocostal joint involvement & $7(33.3)$ \\
\hline Stemoclavicular joint involve ment & $18(85.7)$ \\
\hline Manubrium sternal involvement & $11(52.4)$ \\
\hline Costachondral joint involvement & $6(28.6)$ \\
\hline Hip jont involvement & $10(47.6)$ \\
\hline Sacroilitit is & $10(47.6)$ \\
\hline Osteoit & $10(47.6)$ \\
\hline Entesis & $4(19)$ \\
\hline Uveit's & $3(14.3)$ \\
\hline
\end{tabular}

Abstract AB0848 - Figure 1. Clinical characteristics of patients at diagnosis

PPP: palmoplantar pustulosis, IBP: Inflammatory Back pain

Conclusions: There is a certain diagnostic problem in the SAPHO syndrome. Delay of SAPHO diagnosis was almost 4 years and $62 \%$ of patients had wrong diagnosis before SAPHO syndrome. Anterior chest wall involvement with dermatological findings should be alerting to the physicians. Bone scintigraphy can be helpful to diagnose SAPHO syndrome. It is important to distinguish SAPHO syndrome from other spondyloarthritis and/or psoriatic arthritis because of the poten tial different treatment strategies.

\section{REFERENCE:}

[1] Benhamou CL, Enjolras O, Delrieu F, Prier A, Camus JP, Amor B. Pseudoseptic arthritis and bacterid of Andrews [in French]. Rev Rhum Mal Osteoartic. 1984;51(4):229-231.

Disclosure of Interest: None declared DOI: 10.1136/annrheumdis-2018-eular.5070 